\title{
Effect of Transportation and Low Voltage Electrical Stimulation on Meat Quality Characteristics of Omani Sheep
}

\author{
Isam T. Kadim*, Osman Mahgoub, Waleed Al-Marzooqi \\ and Samera Khalaf \\ Department of Animal and Veterinary Sciences, College of Agricultural and Marine Sciences, \\ Sultan Qaboos University, PO Box 34, Al-Khod 123, Sultanate of Oman
}
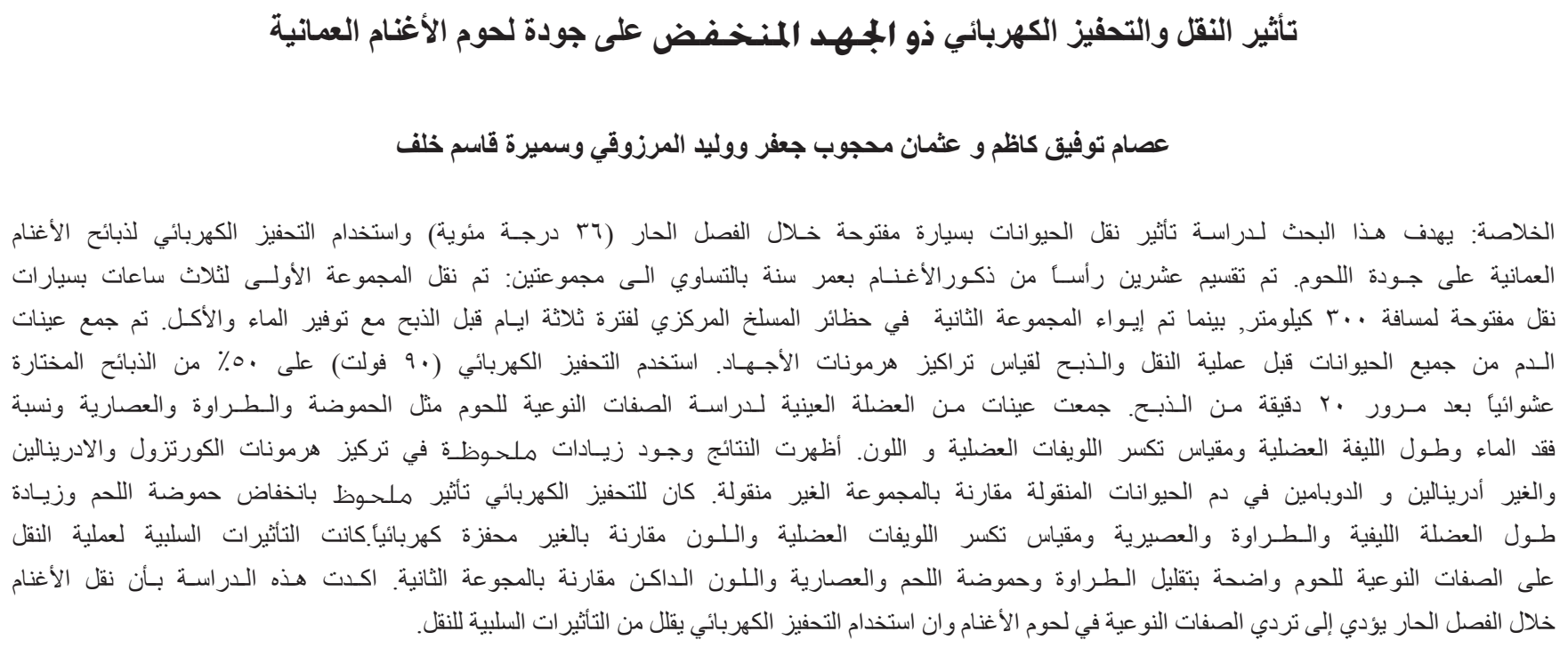

ABSTRACT: The aim of this study was to determine the effects of road transportation during the hot season $\left(36^{\circ} \mathrm{C}\right)$ and low voltage electrical stimulation on meat quality characteristics of Omani sheep. Twenty intact male sheep (1-year old) were divided into two equal groups: $3 \mathrm{hrs}$ transported or non-transported. The transported group was transferred to the slaughterhouse the day of slaughter in an open truck covering a distance of approximately $300 \mathrm{~km}$. The non-transported group was kept in a lairage of a commercial slaughterhouse with ad libitum feed and water for 3 days prior to slaughter. Blood samples were collected from the animals before loading and prior to slaughter in order to assess their physiological response to stress in terms of hormonal levels. Fifty percent of the carcasses from each group were randomly assigned to low voltage $(90 \mathrm{~V})$ at $20 \mathrm{~min}$ postmortem. Muscle ultimate $\mathrm{pH}$, expressed juice, cooking loss percentage, WB-shear force value, sarcomere length, myofibrillar fragmentation index and colour $L^{*}, a^{*}, b^{*}$ were measured on samples from Longissimus dorsi muscles collected $24 \mathrm{hrs}$ postmortem at $2-4^{\circ} \mathrm{C}$. The transported sheep had significantly $(\mathrm{P}<0.05)$ higher cortisol adrenaline, nor-adrenaline, and dopamine levels than the non-transported group. Muscles from electrically-stimulated carcasses had significantly $(\mathrm{P}<0.05)$ lower $\mathrm{pH}$ values, longer sarcomere length, lower shear force value, higher expressed juice, myofibrillar fragmentation index and $L^{*}$ values than those from non-stimulated ones. Transportation significantly influenced meat quality characteristics of the Longissimus dorsi muscle. Muscle ultimate $\mathrm{pH}$ and shear force values were significantly higher, while CIE $L^{*}, a^{*}, b^{*}$, expressed juice and cooking loss were lower in transported than non-transported sheep. This study indicated that pre-slaughter transportation at high ambient temperatures can cause noticeable changes in muscle physiology in sheep. Nevertheless, meat quality of transported sheep can be improved by electrical stimulation post-slaughter.

Keywords: Sheep, transportation, Longissimus dorsi, electrical stimulation, shear force.

\section{Introduction}

Transportation of small ruminants in open trucks between farms and slaughterhouse is a routine practice in the Sultanate of Oman. Transport of live animals has been recognized as a stressful event that has significant economic and welfare implications for animals (Schrama et al., 1994; Kadim et al., 2006). Vibrations and movement of the vehicle are novel to the animals, and therefore likely to elicit a stress response (Dantzer and Normede, 1983). Adverse climatic conditions such as high or low temperatures and high relative humidity are also additional stressors to animals during transport. Animals are inevitably exposed to handling, loading and transportation. All these stressors may increase catecholamine blood concentrations, which may result in compromising cellular and humoral immune functions, reproduction, digestion, growth and other metabolic processes (Dantzer and Mormede, 1983; Nelson and Drazen, 2000). This may also cause metabolic changes that can in turn adversely affect meat quality (Ashmore et al., 1972; Schrama et al., 1994; 
Apple et al., 1995; Kannan et al., 2003; Bond et al., 2004; Kadim et al., 2006). Transportation usually imposes stress on animal and can lead to depletion of muscle glycogen reserves before slaughter that subsequently increase the ultimate $\mathrm{pH}$ of meat, and result in low meat quality characteristics (Kadim et al., 2006). Meat tenderness is one of the most important quality characteristics affected by $\mathrm{pH}$ and temperature (Marsh et al., 1981). Colour is also an important physical property of meat and consumers usually use it as a quality indicator. Moreover, consumers are becoming more aware of the ethics of meat production and prefer meat that has been produced from animals that have not been mistreated (Warris, 1995).

Electrical stimulation can increase postmortem muscle metabolism and hasten the onset of rigor mortis, which might improve the quality characteristics of stressed animals. A rapid $\mathrm{pH}$ decline of electrically stimulated carcasses could potentially result in a brighter coloured meat (King et al., 2004). The objective of the present study was to investigate the impact of road transport and low electrical-stimulation on meat quality characteristics of Omani sheep Longissimus dorsi.

\section{Materials and Methods}

\section{Animals and Treatments}

Twenty Omani intact male sheep (1-year-old) were randomly selected from a homogenous flock fed Rhodesgrass hay and a commercial ruminant concentrate at the Agricultural Experiment Station, Sultan Qaboos University. The experiment was conducted during the hot season when the average ambient temperature was $36^{\circ} \mathrm{C}$. Animals were equally divided into 2 groups and randomly assigned to either non-transported or transported groups. Three days prior to slaughter, the non-transported animals were transferred to a pen under shade in a lairage at Muscat Central Slaughterhouse $(40 \mathrm{~km})$. Feed and water were provided at libitum. On the day of slaughter, the transported animals were transported in an open truck for $3 \mathrm{hrs}$ for a distance of approximately $300 \mathrm{~km}$. A blood sample was collected prior to loading (initial), while a second blood sample collection was taken immediately after the transportation and prior to slaughter. The two blood samples were collected from the non-transported animals at the same time as the transported animals.

\section{Blood Sampling and Analysis}

Blood samples were collected in vacutainer tubes containing $81 \mathrm{~m} \mu \mathrm{L}$ of $15 \%$ EDTA as an anticoagulant. The plasma was separated by centrifugation at $5{ }^{\circ} \mathrm{C}$ for 10 minutes at $3000 \mathrm{rpm}$ then placed in $1.5 \mathrm{ml}$ Eppendorf tubes and stored at $-80{ }^{\circ} \mathrm{C}$. Chemiluminescence immunoassay was used for the determination of plasma hormone levels using a Beckman Coulter Access 2 immunoassay system and reagents. (Beckman Coulter, Inc.). For the extraction of plasma catecholamines (all reagents Chromsystems $\mathrm{GmbH}), 75 \mathrm{mg}$ of acid washed alumina was placed in a 2.0 $\mathrm{ml}$ Eppendorf tube and then $750 \mu \mathrm{L}$ of extraction buffer, 750 $\mu$ Lof plasma, and $100 \mu$ Lof dihydroxybenzoic acid(DHBA) standard $12 \mathrm{ng} / \mathrm{ml}$ were added. This mixture was vortexed for 20 minutes using an autovortex and then centrifuged at $5500 \mathrm{rpm}$ (ALC International microcentrifuge model \# 4214) for 3 minutes and then the supernatant was aspirated. The resulting pellet was washed with $1 \mathrm{ml}$ washing buffer. The mixture was then vortexed as before, centrifuged for 3 minutes, and the wash buffer carefully aspirated. The washing process was repeated three times. To retrieve the catecholamines from the alumina, the pellet was eluted using $240 \mu \mathrm{L}$ elution buffer and vortex for 7 minutes, using the autovortex, centrifuged at 11500 rpm for 5 minutes and the supernatant containing the catecholamines and internal standard was transferred carefully to a clean vial without disturbing the alumina layer. This supernatant was immediately analyzed using an HPLC with an electrochemical detector (Waters 600S, 464 ECD and 717 Autosampler). Results were acquired and processed using Millenium ${ }^{32}$ software (Waters).

\section{Carcass Electrical Stimulation}

Animals were slaughtered and dressed at the Muscat Municipality Central Slaughterhouse following Halal methods. A random $50 \%$ of the carcasses within each group were electrically stimulated for $60 \mathrm{~s}, 20$ minutes postmortem using a low-voltage stimulator (Voltage, 90 V; AgResearch, V1.3-R3B. New Zealand). Carcasses were kept at ambient temperature $\left(20-25{ }^{\circ} \mathrm{C}\right)$ until placed in a chiller $\left(2-4^{\circ} \mathrm{C}\right)$ at $100 \pm 5$ min postmortem.

\section{Meat Quality Evaluation}

The carcasses were chilled for $24 \mathrm{~h}$ at $2-3{ }^{\circ} \mathrm{C}$ before the Longissimus dorsi muscles were removed from the left. The muscles were placed in plastic bags then frozen at $-20{ }^{\circ} \mathrm{C}$ until processing. The muscles were evaluated for a range of quality characteristics including ultimate muscle $\mathrm{pH}$, expressed juice, percent cooking loss, Warner-Bratzler shear force value, sarcomere length, myofibrillar fragmentation index and colour $L^{*}, a^{*}$, $b^{*}$ were determined. The ultimate $\mathrm{pH}$ was assessed in homogenates at $20-22{ }^{\circ} \mathrm{C}$ (using a Ultra Turrax T25 homogenizer) of duplicate $1.5-2 \mathrm{~g}$ of muscle tissue in $10 \mathrm{ml}$ of neutralized 5-mM sodium iodoacetate and the $\mathrm{pH}$ of the slurry measured using a Metrohm $\mathrm{pH}$ meter (Model No. 744) with a glass electrode. Chilled muscle samples (13 mmx13 mm cross section) for assessment of shear force by a digital Dillon Warner-Bratzler (WB) shear were prepared from muscle samples cooked in a water bath at $70{ }^{\circ} \mathrm{C}$ for $90 \mathrm{~min}$. The cooked samples were carefully dried with tissues to remove excess surface moisture and re-weighed to determine cooking losses. Sarcomere length by laser diffraction was determined using procedure described by Cross et al. (1980/1981). Expressed juice was assessed by a filter paper method, as the total wetted area less the meat area $\left(\mathrm{cm}^{2}\right)$ relatively to the weight of the sample (g). Myofibrillar fragmentation index (MFI) was measured using a modification of the 
Table 1. Effects of road transportation on hormonal concentrations in plasma of Omani sheep.

\begin{tabular}{|c|c|c|c|c|}
\hline \multirow[b]{2}{*}{ No. Samples } & & \multicolumn{2}{|c|}{ Treatment } & \multirow{2}{*}{ SEM } \\
\hline & & Transported & Non-transported & \\
\hline \multirow[t]{3}{*}{ Cortisol (nmol/1) } & Initial & $20.9^{\mathrm{a}}$ & 20.6 & 2.91 \\
\hline & Final & $38.9^{\mathrm{b}}$ & 21.1 & 2.65 \\
\hline & Sign. & $* *$ & NS & \\
\hline \multirow[t]{3}{*}{ Adrenaline (ng/ml) } & Initial & $1.61^{\mathrm{a}}$ & 1.59 & 0.15 \\
\hline & Final & $2.15^{\mathrm{b}}$ & 1.60 & 0.34 \\
\hline & Sign. & $*$ & NS & \\
\hline \multirow[t]{3}{*}{ Dopamine $(\mathrm{ng} / \mathrm{ml})$} & Initial & $0.72^{\mathrm{a}}$ & 0.71 & 0.17 \\
\hline & Final & $0.99^{\mathrm{b}}$ & 0.71 & 0.13 \\
\hline & Sign. & $*$ & NS & \\
\hline \multirow[t]{3}{*}{ Nor-adrenaline (ng/ml) } & Initial & $0.19^{\mathrm{a}}$ & 0.20 & 0.021 \\
\hline & Final & $0.38^{\mathrm{b}}$ & 0.21 & 0.027 \\
\hline & Sign. & * & NS & \\
\hline
\end{tabular}

SEM: Standard error of mean, Sign. NS not significant, $* \mathrm{P}<0.05, * * \mathrm{P}<0.01$.

method of Johnson et al. (1990). This measured the proportion of muscle fragments that passed through a 231$\mu \mathrm{m}$ filter after the sample had been subjected to a standard homogenization treatment. A $5 \mathrm{~g}( \pm 0.5 \mathrm{~g})$ sample of diced $\left(6 \mathrm{~mm}^{3}\right.$ pieces) was added to $50 \mathrm{ml}$ of cold physiological saline $(85 \% \mathrm{NaCl})$ plus five drops of antifoam A emulsion (Sigma Chemical A5758) in a $50 \mathrm{ml}$ graduated cylinder, and homogenized at $1 / 4$ speed using an $18 \mathrm{~mm}$ diameter shaft on an Ultra-Turrax homogenizer for 30 -s periods separated by a 30 -s rest period. The homogenate was poured into a weighed filter $(231 \times 231 \mu \mathrm{m}$ holes $)$. The filter typically ceased dripping after $2-3 \mathrm{~h}$, at which time they were dried at $26-28^{\circ} \mathrm{C}$ in an incubator for $40 \mathrm{~h}$ before being reweighed. The MFI values presented herein were calculated as 100 minus the percentage of the initial meat sample weight that remained on the filter. Approximately 60 min after exposing the fresh surface, CIE $L^{*}, a^{*}, b^{*}$ light reflectance coordinates of the muscle surface were measured at room temperature $\left(25 \pm 2{ }^{\circ} \mathrm{C}\right)$ using Minolta Chroma Meter CR-300 (Minolta Co., Ltd., Japan), with a colour measuring area $1.1 \mathrm{~cm}$ diameter. It was calibrated using a Minolta calibration plate $\left(L^{*}=97.59, a^{*}=-5.00\right.$, $\left.b^{*}=+6.76\right)$. The $L^{*}$ value relates to Lightness; the $a^{*}$ value to Red-Green hue where a positive value relates to the red intensity; and the $b^{*}$ value to the Yellow-Blue where a positive value relates to yellow. The average of two measurements from each sample was recorded as the colour coordinate value of the sample.

\section{Statistical Analysis}

The effect of transportation and electrical stimulation on blood serum parameters, and meat quality were analyzed using GLM procedures for analysis of variance procedure (SAS, 1993). The first blood sample was regarded as an initial value and the second blood sample as final value. Both samples were taken from the same animal; therefore SAS repeated measurement analysis was used. Differences between means were assessed using the leastsignificant-difference procedure. Interaction between the transportation and electrical stimulation were excluded from the model when not significant $(\mathrm{P}>0.05)$.

\section{Results and Discussion}

\section{Blood Serum Hormonal Levels}

Physiological parameters such as cortisol, dopamine, adrenaline and nor-adrenaline have been proposed as sensitive indicators of physiological stress response in 
Table 2. Effect of transportation and electrical stimulation on a range of Longissimus dorsi muscle quality characteristics (Least square means) of Omani sheep.

\begin{tabular}{|c|c|c|c|c|c|c|c|c|}
\hline & \multicolumn{2}{|c|}{ Transported } & \multicolumn{2}{|c|}{ Non-transported } & \multirow[b]{2}{*}{ SEM } & \multicolumn{3}{|c|}{ Significance } \\
\hline & $\begin{array}{l}\text { Stimu- } \\
\text { lated }\end{array}$ & $\begin{array}{l}\text { Non- } \\
\text { Stimulated }\end{array}$ & $\begin{array}{l}\text { Stimu- } \\
\text { lated }\end{array}$ & $\begin{array}{l}\text { Non- } \\
\text { Stimulated }\end{array}$ & & Transport & $\begin{array}{l}\text { Stimu- } \\
\text { lation }\end{array}$ & Interaction \\
\hline No. samples & 5 & 5 & 5 & 5 & & & & \\
\hline Ultimate $\mathrm{pH}$ & $5.72^{\mathrm{b}}$ & $5.86^{\mathrm{c}}$ & $5.61^{\mathrm{b}}$ & $5.71^{\mathrm{b}}$ & 0.05 & $*$ & $*$ & NS \\
\hline Expressed juice $^{2}$ & $26.5^{\mathrm{b}}$ & $23.7^{\mathrm{a}}$ & $30.0^{\mathrm{c}}$ & $26.2^{\mathrm{b}}$ & 1.53 & $*$ & $*$ & NS \\
\hline Cooking loss $\%$ & $22.7^{\mathrm{b}}$ & $20.9^{\mathrm{a}}$ & $26.7^{\mathrm{c}}$ & $22.8^{\mathrm{b}}$ & 0.64 & $*$ & $*$ & NS \\
\hline Shear force value & $5.17^{\mathrm{b}}$ & $7.35^{\mathrm{c}}$ & $3.63^{\mathrm{a}}$ & $5.21^{\mathrm{b}}$ & 0.61 & $* *$ & $* *$ & NS \\
\hline Sarcomere length $(\mu \mathrm{m})$ & $1.49^{\mathrm{a}}$ & $1.67^{\mathrm{b}}$ & $1.51^{\mathrm{ab}}$ & $1.75^{\mathrm{c}}$ & 0.07 & $*$ & $*$ & NS \\
\hline Myofibrillar fragmentation index & $78.8^{\mathrm{b}}$ & $76.9^{\mathrm{a}}$ & $87.7^{\mathrm{d}}$ & $82.9^{c}$ & 0.63 & $*$ & $*$ & $*$ \\
\hline $\mathrm{L}^{*}$ (lightness) & $36.7^{\mathrm{ab}}$ & $36.2^{\mathrm{a}}$ & $38.4^{\mathrm{b}}$ & $37.5^{\mathrm{ab}}$ & 0.73 & NS & $*$ & NS \\
\hline $\mathrm{a}^{*}$ (redness) & $14.4^{\mathrm{ab}}$ & $13.8^{\mathrm{a}}$ & $14.2^{\mathrm{ab}}$ & $15.7^{\mathrm{b}}$ & 0.58 & NS & NS & $*$ \\
\hline b* (yellowness) & 5.55 & 5.19 & 5.22 & 5.93 & 0.26 & NS & NS & $*$ \\
\hline
\end{tabular}

${ }^{a b c}$ Means within the same row with different superscripts were significantly different $(\mathrm{P}<0.05) .{ }^{2}$ Expressed juice $=$ water area $\left(\mathrm{cm}^{2}\right) / \mathrm{sample}$ weight (g), ${ }^{3}$ Warner-Bratzler shear force value.

animals that have been exposed to road transportation (Kadim et al., 2006). In the current study, blood parameter values were compared between the transported and nontransported sheep groups to investigate the effects of road transportation on sheep at high ambient temperatures (36 $\left.{ }^{\circ} \mathrm{C}\right)$ (Table 1). The ambient temperature in the present study was above the suggested upper limit of ruminant heat tolerance $\left(35-40{ }^{\circ} \mathrm{C}\right)$ (Yousef, 1985; Lu, 1989). According to Ali et al. (2006), measurement of cortisol is a valuable tool in stressed animals due to a graduated response depending on the severity of the stressor. In the present study, cortisol concentrations were still significantly $(\mathrm{P}<0.01)$ higher $3 \mathrm{hrs}$ after the start of transportation. A similar conclusion was reported by Kadim et al. (2006). Nwe et al. (1996) and Kannan et al. (2000) reported that plasma cortisol concentration increased within $30 \mathrm{~min}$ after the beginning of transport and reached a peak value at $1 \mathrm{hr}$ in goats. The Omani sheep transported the same day to slaughter had significantly higher $(\mathrm{P}<0.01)$ plasma cortisol levels than their non-transported counterpart sheep. This indicates that $3 \mathrm{hrs}$ of transportation in an open truck under Omani conditions $\left(36^{\circ} \mathrm{C}\right)$ appears to produce stress in sheep. Broom et al. (1996), Al-Kindi et al. (2005) Ali et al. (2006) and Kadim et al. (2006) examined a range of plasma stress indicators in transported sheep and found that plasma cortisol levels were higher in transported sheep during 2-3 hrs of the transportation in comparison with the non-transported animals. Moreover, Ruiz-De-La-Torre et al. (2001) found that the level of cortisol was higher after $4 \mathrm{hrs}$ on a rough journey. The lower hormone values in the non-transported sheep indicate that there was sufficient time for recovery from stress and also the shorter distance and time of transport.

Adrenaline, dopamine and nor-adrenaline concentrations were significantly $(\mathrm{P}<0.05)$ higher in the transported than non-transported sheep (Table 1). Similarly, Kadim et al. (2006) found that transportation of Omani sheep for $2 \mathrm{hrs}$ significantly increased concentrations of adrenaline, dopamine and nor-adrenaline compared to non-transported animals. Adrenaline levels increased in sheep after 10 min of transportation with little change in nor-adrenaline level (Parrott et al., 1994). These findings indicated that levels of these hormones stay elevated for at least $3 \mathrm{hrs}$ after transportation. Release of adrenaline enables animals to mobilize body resources quickly for metabolic requirements in response to stress (Dantzer and Mormede, 1983).

\section{Meat Quality}

An elevated ultimate $\mathrm{pH}$ is a consequence of low preslaughter glycogen as a result of pre-slaughter stress including road transportation (Gregory and Grandin, 1998; Geesink et al., 2001; Kannan et. al., 2003; Honikel, 2004; Kadim et al., 2006). Meat from transported sheep had significantly $(\mathrm{P}<0.05)$ higher ultimate $\mathrm{pH}$ value than meat from sheep that were non-transported (Table 2). Kadim et al. (2006) also found that 2 hrs-transportation had a significant effect on muscle-ultimate $\mathrm{pH}$ of the Omani sheep. Different types of stressors may elicit varying degrees of responses in animals. Ruiz-De-La-Torre et al. (2001) found that transportation of sheep on a rough road for $4 \mathrm{hrs}$ significantly increased ultimate $\mathrm{pH}$ compared to those transported on a smooth road. Similarly, muscles from stressed sheep had significantly higher ultimate $\mathrm{pH}$ values than non-stressed counterparts (Apple et al., 1995). Transportation not only includes physical stress, but also emotional stress caused by loading and unloading, noise, vibration and social disruptions. The effort needed by the sheep to keep their balance while the vehicle moves is demanding in terms of energy requirements leading to 
depletion of glycogen and consequently decreasing muscle pH (Tarrant and Grandin, 1993; Apple et al., 1995).

The ultimate $\mathrm{pH}$ of muscle is a major determinant of meat quality (Watanabe et al., 1996) and is related to the rate of glycogen and liberation of lactic acid via glycolysis pre- and post-slaughter. The $\mathrm{pH}$ affects meat tenderness and water-holding capacity (Watanabe et al., 1996). Ultimate $\mathrm{pH}$ value of meat is the result of a combination of many factors including pre-slaughter handling, postmortem treatment, glycogen store and muscle physiology (Ashmore et al., 1973; Marsh, 1977; Thompson, 2002). There were significant $(\mathrm{P}<0.05)$ differences in ultimate $\mathrm{pH}$ at $24 \mathrm{hrs}$ postmorte $m$ between the stimulated and non-stimulated muscles of sheep (Table 2). In the present study, electrical stimulation appears to increase early postmortem glycolysis in muscle samples (Table 2). Similarly, Geesink et al. (2001) found that ultimate $\mathrm{pH}$ from stimulated sheep carcass was significantly lower than that of non-stimulated carcass. In contrast, Bond et al. (2004) and Devine et al. (2006) have found that ultimate $\mathrm{pH}$ of Longissimus muscle was not affected by electrical stimulation.

Water retention of meat is primarily caused by immobilization of tissue water within the myofibrillar system (Hamm, 1981). Applying pressure can cause a shift of water from the intercellular into the extracellular space and then onto the meat surface as a result of structural alterations at the level of the myofilament structure. Expressed juice of sheep muscle was significantly affected by transportation and low voltage electrical stimulation (Table 2). Samples from transported sheep had significantly $(\mathrm{P}<0.05)$ lower expressed juice and cooking loss than muscles from non-transported ones (Table 2). Decreased cooking loss percentage is a reflection of the increased water-holding capacity (decrease expressed juice) associated with meat of high ultimate $\mathrm{pH}$ (Bouton et al., 1971). Similarly, Apple et al. (1995) found that muscles from stressed lambs had lower $(\mathrm{P}<0.01)$ cooking loss than that from non-transported animals. In contrast, Bond et al. (2004) found that muscles from exercisestressed sheep were significantly higher than those from non-exercised animals. They concluded that the mechanism causing greater water loss in the muscle of exercise-stressed lambs is unknown.

Expressed juice was significantly higher $(\mathrm{P}<0.05)$ for stimulated than for non-stimulated muscle samples. The increase in myofibrillar expressed juice of electricallystimulated muscles may be partly due to denaturised sarcoplasmic proteins in the myofibrillar fraction (Eikelenboom and Smulders, 1986). However, Whiting et al. (1981) and Bond et al. (2004) found that electrical stimulation had no effect on water-holding capacity of lamb Longissimus dorsi muscle. The differences between samples from stimulated and non-stimulated muscle may probably be due to shrinkage of myofibrils as the postmortem $\mathrm{pH}$ fall causes denaturation of protein (Offer and Knight, 1988). The decline in $\mathrm{pH}$ after slaughter was much slower in non-stimulated than stimulated Longissimus dorsi muscles. Moreover, the thin and thick filaments interaction (sarcomere length) significantly $(\mathrm{P}<0.05)$ differed between stimulated and non-stimulated muscles (Table 2).

Muscles from non-transported sheep had a significantly lower shear force value compared to transported sheep (Table 2). In agreement with the present study, Kadim et al. (2006) found that meat from non-transported sheep was significantly more tender than that from transported ones. Apple et al. (1995) also found that muscles from non-transported sheep had lower shear values than stressed ones. In contrast, Chrystall et al. (1982) found that the muscle from sheep chased to exhaustion by dogs was tenderer than those from their non-transported counterparts. Decreased glycogen reserves and increased muscle temperature during transport resulted in muscle with a $\mathrm{pH}$ above 6.0 (Marsh, 1983), which may activate calpain proteases (Koohmaraie, 1988). In accordance with the shear-value results, muscles from the transported sheep had significantly $(\mathrm{P}<0.05)$ shorter sarcomere lengths than those from non-stimulated animals (Table 2).

Muscles from non-stimulated carcasses had a significantly $(\mathrm{P}<0.01)$ higher shear force value compared to stimulated carcasses (Table 2). The most positive advantage for electrical stimulation observed in the present study was similar to reports by Chrystall and Hagyard (1976); Riley et al. (1981); Kadim et al. (1993); Polidori et al. (1999); Geesink et al. (2001); and Devine, et al. (2006). According to Kadim et al. (1993), electrical stimulation of muscles soon after slaughter improved tenderness most probably by hastening the onset of rigor mortis rather than through processes that rapidly reduce muscle $\mathrm{pH}$ in sheep and consequently avoid toughening effects of cold shortening and thaw shortening. Shearforce values of muscles chilled at different rates were significantly reduced by electrical stimulation compared with non-stimulated ones (Shorthose et al., 1986). Hwang et al. (2003) stated that stimulation may improve tenderness either through effects on physical alteration and/or acceleration of energy turnover during and after the stimulation. Moreover, Ho, et al. (1996) and Luo, et al. (2008) found a relationship between myofibrillar disruption and improved tenderness of meat. Luo et al. (2008) reported that stimulation resulted in ultrastructural changes in beef Longissimus muscle, which lowers the resistance to shearing force (Hopkins et al., 2000). In the present study, electrically-stimulated sheep Longissimus dorsi muscle had significantly $(\mathrm{P}<0.05)$ longer sarcomere length than non-stimulated muscles. Similar findings were reported by Whiting et al. (1981) and Geesink et al. (2001) for lambs.

The Longissimus dorsi muscle from transported sheep had significantly lower $(\mathrm{P}<0.05) \mathrm{CIE} \mathrm{L}^{*}$ value than nontransported counterpart (Table 2). This indicates that muscles from transported sheep were darker than muscle from non-transported sheep. The lower $L^{*}$ values of 
muscle from transported sheep in the present study are similar to those reported by Apple, et al. (1995) who found lower values of $L^{*}$ for muscle from lambs subjected to stress. The type and intensity of transportation had an effect on meat colour. Ruiz-De-La-Torre et al. (2001) found that redness of sheep muscle which was transported on a rough road for $4 \mathrm{hrs}$ was significantly higher than for those transported smoothly. Bond et al. (2004) found that the colour of meat from stressed sheep was darker than those from non-transported animals. When muscle $\mathrm{pH}$ increased to above 6.0 , CIE a* values decreased below 16.0 (Apple et al., 1995). In the present study, mean a* values of the Longissimus dorsi muscles from transported sheep were below 16.0, indicating that the dark colour was effectively produced by $3 \mathrm{hrs}$ of transportation due to depletion of muscle glycogen reserves before slaughter (Warriss et al., 1990). Muscle darkness is highly related to $\mathrm{pH}$ change and occurs at a $\mathrm{pH}$ of approximately 6.0 (MacDougall and Jones, 1981). Mitochondrion oxygen uptake is more active at $\mathrm{pH}$ values greater than 6.0 (Lawrie, 1958). Postmortem glycolysis acid formation is insufficient to prevent mitochondrial respiration, thus allowing myoglobin to be deoxygenated and causing the muscle to remain dark (Egbert and Cornforth, 1986). Ultimate $\mathrm{pH}$ can influence colour independently of meat myoglobin content (Ledward, 1985), which may explain differences between the transported and non-transported muscles in the present study.

The color of meat is influenced by several individual factors and their interactions. There was increased muscle lightness $\left(L^{*}\right)$ of the Longissimus dorsi muscles from the electrical stimulated carcasses (Table 2). This suggested that early postmortem conditions of these muscles favored protein denaturation (Warriss and Brown, 1987). High muscle temperatures combined with low muscle $\mathrm{pH}$ values during early postmortem are associated with increased protein denaturation. However, Bond et al. (2004) found that electrical stimulation of sheep carcasses did not improve muscle lightness.

Transportation of sheep for $3 \mathrm{hrs}$ had a significant $(\mathrm{P}<0.05)$ effect on myofibrillar fragmentation index of the Longissimus dorsi muscles (Table 2). The myofibrillar fragmentation index from non-transported muscle was significantly $(\mathrm{P}<0.05)$ higher than those from transported one by $8.9 \%$. Significantly lower myofibrillar fragmentation index and shorter sarcomere lengths for the transported-non-stimulated sheep are consistent with the tougher meat from that group. The high myofibrillar fragmentation index in stimulated-non-transported sheep may have been caused by myofibrils easily broken into shorter segments.

Myofibril fragmentation index has been used as an indicator of postmortem proteolysis in various types of meat (Lametsch et al., 2007) as it accounts for differences in the rate of postmortem tenderization of meat (Nagaraj et al., 2005). The latter authors concluded that structural changes occurring in meat after slaughter are generally believed to be caused by interactions of myofibrillar proteins in the muscle. Low voltage electrical stimulation and transportation had a significant $(\mathrm{P}<0.05)$ effect on myofibrillar fragmentation index of the sheep muscle (Table 2). The myofibrillar fragmentation index from transported muscle was significantly $(\mathrm{P}<0.05)$ lower than that from non-transported one (Table 2).

\section{Conclusions}

Transportation of sheep for $3 \mathrm{hrs}$ in an open truck at high ambient temperatures $\left(36{ }^{\circ} \mathrm{C}\right)$ led to higher blood concentrations of cortisol, adrenaline, nor-adrenaline and dopamine. Meat quality characteristics were also worsened by transportation during hot ambient temperatures. Low voltage electrical stimulation can be used to reduce the deleterious effects of transportation on meat quality.

\section{References}

Ali, B.H., A.A. Al-Qarawi and H.M. Mousa. 2006. Stress associated with road transportation in desert sheep and goats, and the effect of pretreatment with xylazine or sodium betaine. Research Veterinary Science 80:343348.

Al-Kindi, A., I.T. Kadim, I.Y. Mahmoud, O. Mahgoub, J. Plude and M. Al-Maani. 2005. Physiological response of two age groups of Omani sheep to short road transportation in relation to circulating levels of gonasotropins, cortisol, thyroid hormones, sex steroids and plasma chemistry. Journal of Animal Veterinary Advance 4:742-746.

Apple, J.K, M.E. Dikeman, J.E. Minton, R.M. McMurphy, M.R. Fedde, D.E. Leith and J.A. Unruh. 1995. Effects of restraint and isolation stress and epidural blockade on endocrine and blood metabolite status, muscle glycogen metabolism and incidence of dark-cutting longissimus muscle of sheep. Journal of Animal Science 73:22952307.

Ashmore, C.R., W. Parker and L. Doerr. 1972. Respiration of mitochondria isolated from dark-cutting beef: postmortem changes. Journal of Animal Science 34: 46-48.

Ashmore, C.R., F. Carroll, J. Doerr, G. Tompkins, H. Stokes and W. Parker. 1973. Experimental prevention of dark-cutting meat. Journal of Animal Science 35: 33-36.

Broom, D.M., J.A. Goode, S.J. Hall, D.M. Lloyd and R.E. Parrot. 1996. Hormonal and physiological effects of a 15 $h$ road journey in sheep: Comparison with the responses to loading, handling and penning in the absence of transport. British Veterinary Journal 152:593-605.

Bond, J.J., L.A. Can and R.D. Warner. 2004. The effect of exercise stress, adrenaline injection and electrical stimulation on changes in quality attributes and proteins in Semimbranosus muscle of lamb. Meat Science 68: 469-477.

Bouton, P.E., P.V. Harris and W.R. Shorthose. 1971. Effect of ultimate $\mathrm{pH}$ upon the water-holding capacity 
and tenderness of mutton. Journal of Food Science 36: 435-439.

Chrystall, B.B. and C.J. Hagyard. 1976. Electrical stimulation and lamb tenderness. New Zealand Journal of Agriculture Research 19:7-11.

Chrystall, B.B., C.E. Devine, M. Snodtrass and S. Ellery. 1982. Tenderness of exercise-stressed lambs. New Zealand Journal of Agriculture Research 25:331.

Cross, H.R., R.L. West and T.R. Dutson. 1980/1981. Comparisons of methods for measuring sarcomere length in beef Semitendinosus muscle. Meat Science 5: 261-266.

Dantzer, R. and P. Mormede. 1983. Stress in farm animals: a need for re-evaluation. Journal of Animal Science 57: 6-18.

Devine, C.E., T.E. Lowe, R.W. Wells, N.J. Edwards, J.E. Hocking Edwards, T.J. Starbuck and P.A. Speck. 2006. Pre-slaughter stress arising from on farm handling and its interactions with electrical stimulation on tenderness of lambs. Meat Science 73:304-312.

Eikelenboom, G. and F.J.M. Smulders. 1986. Effect of electrical stimulation on veal quality. Meat Science 16: 103-112.

Egbert, W.R. and D.P. Cornforth. 1986. Factors influencing color of dark cutting beef muscle. Journal of Food Science 51:57, 59\&65.

Geesink, G.H., M.H.D. Mareko, J.D. Morton and R. Bickerstaffe. 2001. Effects of stress and high voltage electrical stimulation on tenderness of lamb Longissimus. Meat Science 57:265-271.

Gregory, N.G. and T. Grandin. 1998. Animal Welfare and Meat Science. CAB International, Wallingford, UK.

Hamm, R. 1981. Postmortem changes in muscle affecting the quality of comminuted meat products. In: Development in Meat Science. R.P. Lawrie (Editor), 2: 93-124. London, England. Applied Sci. Pub.

Ho, C.Y., M.H. Stromer and R.M. Robson. 1996. Effect of electrical stimulation on postmortem titin, nebulin, desmin and troponin $\mathrm{T}$ degradation and ultrastructural changes in bovine longissimus muscle. Journal of Animal Science 74:1563-1575.

Honikel, K.O. 2004. Conversion of muscle to meat. In: Encyclopedia of Meat Science. W.J. Jensen, C.E. Devine and M. Dikeman (Editors), pp. 314-318. Oxford: Academic Press.

Hopkins, D.L. and G.R. Ferrier. 2000. The tenderness of lamb meat after low voltage stimulation under commercial conditions. Asian-Australasian Journal of Animal Science 13 Supplement, B: 356-357.

Hwang, I.H., C.E. Devine and D.L. Hopkins. 2003. The biochemical and physical effects of electrical stimulation on beef and sheep meat tenderness. Meat Science 65:677-691.

Johnson, M.H., C.R. Calkins, R.D. Huffman, D.D. Johnson and D.D. Hargrove. 1990. Differences in cathepsins $\mathrm{B}+\mathrm{L}$ and calcium dependent protease activities among breed type and their relationship to beef tenderness. Journal of Animal Science 8:2371-2379.

Kadim, I.T., R.W. Purchas, A.S. Davies, A.L. Rae and R.A. Barton. 1993. Meat quality and muscle fibre type characteristics of southdown rams from high and low backfat selection lines. Meat Science 33:97-109.

Kadim, I.T., O. Mahgoub, A.Y. Al-Kindi, W. Al-Marzooqi, N. Al-Saqri, M. Almaney and I.Y. Mahmoud. 2006. Effect of transportation at high ambient temperatures on physiological responses, carcass and meat quality characteristics in two age groups of Omani sheep. Asian-Australasian Journal of Animal Science 20: 424-431.

Kannan, G., T.H. Terrill, B. Kouakou, O.S. Gazal, S. Gelaye, E.A. Amoah and S. Samake. 2000. Transportation of goats: Effects on physiological stress responses and live weight loss. Journal of Animal Science 78:1450-1457.

Kannan, G., B. Kouakou, T.H. Terrill and S. Gelaye. 2003. Endocrine, blood metabolite and meat quality changes in goats as influenced by short-term, preslaughter stress. Journal of Animal Science 81:1499-1507.

King, D.A., K.L. Voges, D.S. Hale, D.F. Waldron, C.A. Taylor and J.W. Savell. 2004. High voltage electrical stimulation enhances muscle tenderness, increases aging response, and improves muscle color from cabrito carcasses. Meat Science 68:529-535.

Koohmaraie, M. 1988. The role of endogenous proteases in meat tenderness. Reciprocal Meat Conference Proceedings 41:89-77.

Lametsch, R., J.C. Knudsen, P. Ertbjerg, N. Oksbjerg and M. Therkildsen. 2007. Novel method for determination of myofibril fragmentation postmortem. Meat Science 75:719-724.

Lawrie, R.A. 1958. Physiological stress in relation to darkcutting beef. Journal of Science Food Agriculture 9: 721-727.

Ledward, D.A. 1985. Post-slaughter influences on the formation metmyoglobin in beef muscles. Meat Science 15:149-171.

Lu, C.D. 1989. Effects of heat stress on goat production. Small Ruminant Research 2:151-162.

Luo, X., Y. Zhu and G. Zhou. 2008. Electron microscopy of contractile bands in low voltage electrical stimulation beef. Meat Science 80:948-951.

MacDougall, D.B. and S.J. Jones. 1981. Translucency and colour defects of dark-cutting meat and their detection. In: The Problem of Dark-Cutting in Beef. D.E. Hood and P.V. Tarrant (Editors), p. 328. Martinus Nijhoff Publishers, The Hague, The Netherlands.

Marsh, B.B. 1977. The basis of tenderness in muscle foods. Journal of Food Science 42:295-297.

Marsh, B.B. 1983. Effects of early-postmortem muscle $\mathrm{pH}$ and temperature on meat tenderness. Reciprocal Meat Conference Proceedings 36:131-135.

Marsh, B.B., J.V. Lochner, G. Takahashi and D.D. Kragness. 1981. Effects of early postmortem $\mathrm{pH}$ and 
temperature on beef tenderness. Meat Science 5:479483.

Nagaraj, N.S., K.R. Anilakumar and K. Santhanam. 2005. Postmortem changes in myofibrillar proteins of goat skeletal muscles. Journal of Food Biochemistry 29: 152-170.

Nelson, R.J. and D.L. Drazen. 2000. Seasonal changes in stress Reponses. In: Encyclopedia of Stress, Volume 3. Academic Press. USA.

Nwe, T.M., E. Hori, M. Manda and S. Watanabe. 1996. Significance of catecholamines and cortisol levels in blood during transportation stress in goats. Small Ruminant Research 20:129-135.

Offer, G. and P. Knight. 1988. The structural basis of water-holding in meat. In: Development in Meat Science-4. R.A. Lawrie (Editor), pp 63. Elsevier Applied Science, London.

Parrott, R.F., B.H. Misson and C.F. Riva. 1994. Differential stressor effects on the concentrations of cortisol, prolactin and catecholamines in the blood of sheep. Research Veterinary Science 56:234-239.

Polidori, P., S. Lee, R.G. Kauffman and B.B. Marsh. 1999. Low voltage electrical stimulation of lamb carcasses: effects on meat quality. Meat Science 53:179-182.

Riley, R.R., J.W. Savell, G.C. Smith and M. Shelton. 1981. Improving appearance and palatability of meat from ram lambs by electrical stimulation. Journal of Animal Science 52:522-529.

Ruiz-De-La-Torre, J.L., A. Velarde, A. Diestre, M. Gispert, S.J.G. Gall, D.M. Broom and X. Manteca. 2001. Effects of vehicle movements during transport on the stress responses and meat quality of sheep. The Veterinary Record 24:227-229.

SAS, 1993. Statistical Analysis System. SAS/STAT Users Guide, Volume 2, Version 6, Cary, NC.
Schrama, J.W., W. Van Der Hel, A.M. Henken, J. Grossen and M.W.A. Verstefen. 1994. Transport of farm animals: The thermal environment. $40^{\text {th }}$ ICoMST, pp. 85-96. The Hague, Netherlands.

Shorthose, W.R., V.H. Powell and P.V. Harris. 1986. Influence of electrical stimulation, cooling rates and aging on the shear force values of chilled lamb. Journal of Food Science 51:889-928.

Tarrant, V. and T. Grandin. 1993. Transportation of cattle by road. In: Livestock Handling and Transport. T. Grandin (Editor), pp 109-126. Wallingford, CAB International. Thompson, J. 2002. Managing meat tenderness. Meat Science 62:295-308.

Watanabe, A., C.C. Daly and C.E. Devine. 1996. The effects of the ultimate $\mathrm{pH}$ of meat on tenderness changes during aging. Meat Science 42:67-78.

Warriss, P.D., S.C. Kestin, C.S. Young, E.A. Bevis and S.N. Brown. 1990. Effect of preslaughter transport on carcass yield and indices of meat quality in sheep. Journal of Science Food Agriculture 51:517-523.

Warris, P.D. 1995. Ante-mortem factors influencing the yield and quality of meat from farm animals. In: Quality and Quality of Meat from Farm Animals. S.D.M. Jones (Editor), 1-16. CRC Press.

Warriss, P.D. and S.N. Brown. 1987. The relationships between initial $\mathrm{pH}$, reflectance and exudation in pig muscle. Meat Science 20:65-74.

Whiting, R.C., E.D. Strange, A.J. Miller, R.C. Benedict, S.M. Mozersky and C.E. Swift. 1981. Effects of electrical stimulation on the functional properties of lamb muscle. Journal of Food Science 46:434-487.

Yousef, M.K. 1985. Thermoneutral zone. In: Stress Physiology in Livestock, 1:67-74. CRC Press, Boca Raton, FL. 